\title{
The Ergonomic Design of Bent-Handled Wok for Female Cooks' Wok Flipping Task
}

\author{
Swei-Pi Wu ${ }^{1}$, Chien-Chung Jen ${ }^{1}$, Chien-Hsin Yang ${ }^{2}$, Te-Hong Chien ${ }^{3} \&$ Chia-Hui Lin ${ }^{4}$ \\ ${ }^{1}$ Ergonomics Research laboratory, Department of Industrial Engineering and Management Information, Huafan \\ University, Taiwan \\ ${ }^{2}$ Department of Industrial Engineering and Management, Overseas Chinese University, Taiwan \\ ${ }^{3}$ Department of Computer Science \& Information Engineering, Taipei Chengshih University of Science and \\ Technology, Taiwan \\ ${ }^{4}$ Department of Design Marketing, Tungfang Design Institute, Taiwan \\ Correspondence: Swei-Pi Wu, Huafan University, 1, Hua Fan Road, Shihtin Dist, New Taipei City 223, Taiwan, \\ R.O.C. Tel: 886-2-2663-2102. Fax: 886-2-2663-1119. E-mail: spwu@huafan.hfu.edu.tw
}

Received: October 1, 2015 Accepted: November 9, 2015 Online Published: December 28, 2015

doi:10.5539/jfr.v5n1p58 URL: http://dx.doi.org/10.5539/jfr.v5n1p58

\begin{abstract}
Conventional straight-handled woks and the ergonomic bent-handled woks under different wok sizes were evaluated using the psychophysical approach. Twelve female subjects were tested using 15 different woks in a random order. The independent variables were the wok handle angle (with two angles of $25^{\circ}, 10^{\circ}$ for traditional wok, and three angles of $-5^{\circ},-20^{\circ}$ and $-35^{\circ}$ for bent-handled wok) and the wok size (with three diameters of 33 $\mathrm{cm}, 36 \mathrm{~cm}$ and $39 \mathrm{~cm}$ ). The criterion measures included maximum acceptable weight of flipping (MAWF), wrist angle and subjective rating. The results showed both the handle angle and wok size significantly affected the maximum acceptable weight of flipping, wrist angle and subjective rating. The bent-handled wok is superior to the straight-handled wok, and the size-weight illusion effect is significant. In general, a small wok $(33 \mathrm{~cm}$ diameter) with an ergonomic bent handle $\left(-35^{\circ}\right)$ is ideal for females to decrease the risk of upper extremity musculoskeletal disorders when performing the flipping task.
\end{abstract}

Keywords: bent-handled work, wok flipping task , cooking utensil, ergonomic design, psychopysics

\section{Introduction}

The prevalence of upper extremity cumulative trauma disorders (CTDs) has been found related to work activity in varied tasks (Chang et al., 1999; Li, 2002; Roquelaure et al., 2004; Lintula \& Nevala, 2006; McGorry et al., 2014; You et al., 2014). It has been reported hand tools account for a large proportion of cumulative trauma disorders (Aghazadeh \& Mital, 1987; Hsu \& Chen, 1999), such as carpal tunnel syndrome and tendonitis (Waters, 2004). Posture, force, frequency and duration were recognized as key ergonomic risk factors of non-powered hand tools for cumulative trauma disorders (Armstrong et al., 1986; Putz Anderson, 1988; Malchaire et al., 1996). You et al. (2014) verified that prolonged exposure to non-neutral wrist postures is associated with a twofold increased risk for CTS compared with low hoers of exposure to non-neutral wrist posture. To prevent workers from becoming injured due to unnatural postures and repetitive forceful exertion of hand/wrist movements, an ergonomic bent handle idea for hand tool design was introduced (Tichauer \& Gage, 1977; Tichauer, 1978), and verified by many scholars (e.g. Armstrong et al., 1982; Konz, 1986; Lewis \& Narayan, 1993; Hsu \& Chen, 1999; Li, 2002; Wu et al., 2015).

The wok and culinary spatula (turning shovel) are the most indispensable cooking utensils in Oriental kitchens. These two utensils have been used to cook various dishes. For most dishes the cooks need to manipulate both the wok and culinary spatula simultaneously by two hands. In general, the cooks are used to standing still with the preferred hand grasping the handles of the culinary spatula, and the other hand grasping the handle of the wok. To help the food be evenly stirred and heated in the wok, the cooks usually flip the wok with one hand and hold it with a strong grip. The operation of flipping the wok requires repetitive forceful exertion and wrist movements, combined with a static load on the upper arm and shoulder. This action increases the risk of upper extremity musculoskeletal disorders (Silverstein et al., 1986, 1987; Okunribibo \& Haslegrave, 1999; Mital et al., 1999; 
Buckle \& Devereux, 2002; Waters, 2004; Eksioglu, 2006; McGorry \& Lin, 2007).

The wok and culinary spatula are frequently used and for a prolonged period by many cooks. However, their ergonomic properties have not been thoroughly studied. Though the culinary spatula has been studied (Hsu et al., 1994; Wu \& Hsieh, 2002; Wu et al., 2015) the conventional wok with a straight handle has seldom been ergonomically studied (Wu et al., 2011). Wu et al. (2011) investigated the effects of wok size and handle angle on the task of flipping by male cooks. The results showed that both the wok size and handle angle had a significant effect on the maximum acceptable weight of wok flipping, the subjective rating and the subjective ranking. They suggested a small wok (36cm diameter with an ergonomically bent handle $\left(-20^{\circ} \pm 15^{\circ}\right)$ is the optimal design for male cooks. However, it is not clear if these results apply to female cooks. In addition, the wok handle designed by Wu et al. (2011) is to bend down the handles purchased in the market at different angles. Because the handle is bent too low, the handle would touch the ground surface, and the user hand might easily get burned by the stove. The wok handle in the study was redesigned by ourselves. To raise the handle, it is bent upward at a right angle and then bent down at various angles. When the users hold the handle, their hand won't touch the stove fire. It is a patented, innovative design. Therefore, the aim of the present study was to assess the effects of the conventional straight-handled wok, and the ergonomic bent-handled wok with different wok sizes, on the maximum acceptable weight, wrist angle and the subjective rating in an attempt to propose an ergonomic wok to decrease the awkward posture and reduce the physical load on the female cooks.

\section{Methods}

\subsection{Subjects}

Twelve females with at least one year of cooking experience participated in these experiments. The mean ( \pm std) age, height and body weight were: $19.6( \pm 0.67)$ years, $159.84( \pm 5.07) \mathrm{cm}$, and $58.08( \pm 9.90) \mathrm{kg}$, respectively. All subjects were free from any musculoskeletal and cardiovascular disorders, they were asked to sign an informed consent. Each subject was told to avoid participating in strenuous exercise and sleep normally one day before the experiment. The subjects were compensated for their participation in the experiments.

\subsection{Apparatus}

The wrist angle in the palmar flexion/extension and the radial/ulnar deviation planes was measured using a twin-axis Penny and Giles Biometrics electrogoniometer (model XM65). To eliminate the nonnatural postures and repetitive forceful exertion of the wrist, the upward handle of the straight-handled wok was modified to be downward bent handle. Based upon Hsu and Chen (1999), the mean of the natural angle between forearm and grasp center is about $67^{\circ}$, with a standard deviation of $3.8^{\circ}$. This natural angle corresponds to $23^{\circ}$ downwards (between the horizontal line and the handle). In this experiment, beside two conventional straight-handled woks (upward $10^{\circ}$ and $25^{\circ}$ )were used, three bent-handled woks (downward $-5^{\circ},-20^{\circ}$ and $-35^{\circ}$ ) were modified from the conventional wok. In addition, to prevent the stove fire burn the hand when holding the downward handle, the base of wok handle were bent upward vertically as shown in Fig 1. Therefore, the experimental woks used in this study were different from those of used in $\mathrm{Wu}$ et al. (2011), and had obtained a prize of utility model patent. Finally, to test the effect of the wok size and size-weight illusion on the maximum acceptable weight of the flipping task, according to a simple survey among housewives, the three most preferred wok sizes $(33 \mathrm{~cm}, 36 \mathrm{~cm}$ and $39 \mathrm{~cm}$ ) were used. The weight of the three woks were $905 \mathrm{~g}, 1,094 \mathrm{~g}$ and $1,194 \mathrm{~g}$, for the $33 \mathrm{~cm}, 36 \mathrm{~cm}$ and $39 \mathrm{~cm}$ diameter woks, respectively. Here, a total of 15 woks were used in this study. Fig 1 depicts the size and shape of the woks used in this experiment.

\subsection{Experimental Design}

The experiment used a two-factor, within-subject design. The independent variables were the wok size (with three diameters of $33 \mathrm{~cm}, 36 \mathrm{~cm}$ and $39 \mathrm{~cm}$ ) and the wok handle angle (with two angles of $25^{\circ}, 10^{\circ}$ for straight-handled wok; and three angles of $-5^{\circ},-20^{\circ}$ and $-35^{\circ}$ for bent-handled wok). Fifteen size and angle combinations were used in the experimental conditions. The experimental task was the same as Wu et al. (2011). The criteria measures were the maximum acceptable weight of flipping (MAWF), wrist angle(palmar flexion/extension and radial/ulnar deviation), and the subjective rating under various flipping task conditions. These criteria measures represented psychophysical, biomechanical and physiological, respectively. To prevent the effects of cooking utensils, the size of the cooking utensils was controlled as follows: the handle of culinary turning shovel was $25 \mathrm{~cm}$ length with $25^{\circ}$ for the lifting angle, the height of the gas stove was $9 \mathrm{~cm}$, and the container size was $24 \phi \mathrm{cm} \times 12 \mathrm{~cm}$ height. The working platform height was adjusted according to the subject's knuckle height in order to standardije the distance between shoulder and stove. The temperature and relative humidity in the laboratory were about $24^{\circ} \mathrm{C}$ and $50 \%$, respectively. Figure 2 demonstrates the laboratory setting. 


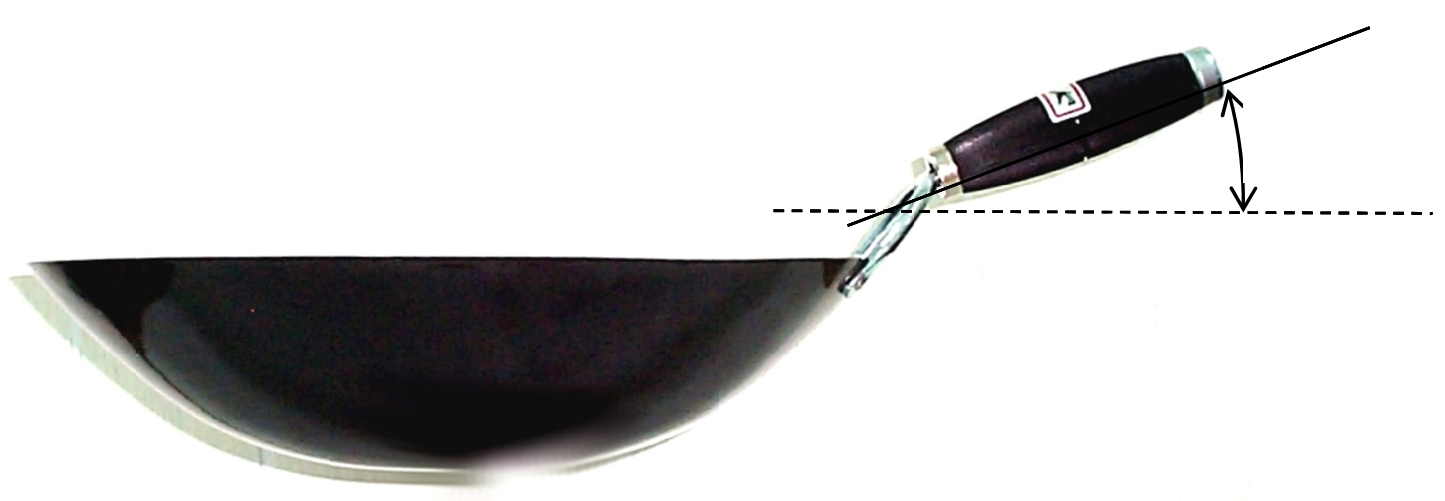

(a) A conventional wok with a straight handle

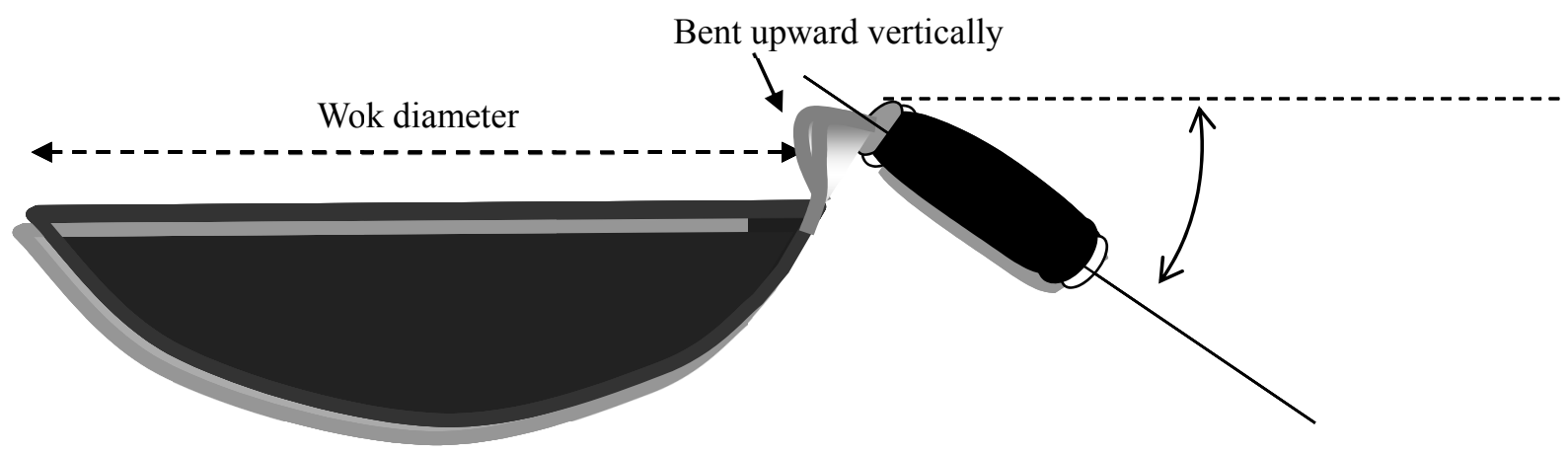

(b) An ergonomically designed bent-handled wok

Figure 1. Dimensions and specification of woks used in the study

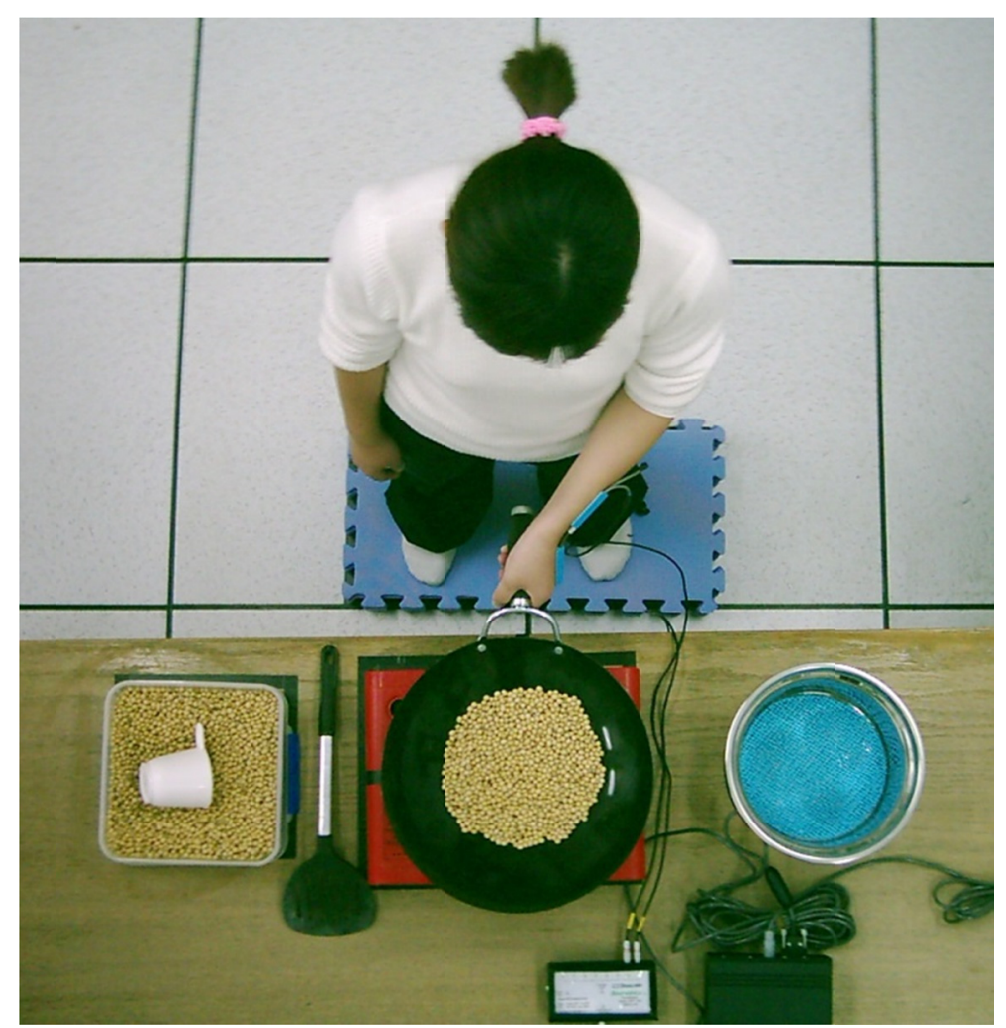

Figure 2. The workplace layout 


\subsection{Procedure}

Before data collection, four training sessions were conducted to gradually condition the subjects to the different tasks and enable them to gain experience in adjusting the flipping weight and force. Each session lasted half an hour.

In the first training session the subjects were asked to use the woks with the straight-handle angle of $10^{\circ}$ in three wok sizes $(33 \mathrm{~cm}, 36 \mathrm{~cm}$ and $39 \mathrm{~cm})$ to practice the flipping task. This was done to get them familiarize with the flipping task and the muscle group used according to the instructions given by the speaker. In the second to fourth training sessions, the subjects were asked to practice flipping five woks in a random order. They practiced flipping each wok for 2 minutes, including "adjusting the weight" and "flipping the wok after determining the weight". They practiced adjusting the weight of the food in the wok using the psychophysical approach to determine the maximum acceptable weight.

After training, each subject performed the flipping task using all 15 woks in random order. On any given day, data for only one experimental combination was collected for each subject. The procedures for collecting each data set included: (1) reading the psychophysical instructions (Ciriello et al., 1983); (2) performing the warming-up exercises, the experimenter led the subjects in stretching/rotary exercises, for the shoulder, arm, wrist and palm, four times; (3) wearing the electrogoniometer on the non-dominant hand; (4) adjusting the weight in the wok and performing the simulated flipping the wok tasks; and (5) filling the subjective rating scale.

\subsection{Simulated Wok Flipping}

When the subjects formally participated in the wok flipping experiment, they were required to read the psychophysical instructions first and then perform the warming-up exercise for ten minutes. Then, the subjects wore the electrogoniometer to measure the angles of their wrist. The experimental stage was then begun.

The experimental stage was divided into three steps. The first step involved "the subjects adjusting the starting weight according to their perceived exertion", lasting one minute. The subject grasped the handle of the wok with her non-dominant hand, and adjusted the amount of soybeans in the wok with her dominant hand holding the measuring glass according to her perceived exertion until she could accept the weight in the wok while performing the flipping task.

The second step followed, which was "flipping the wok and adjusting the weight", lasting three minutes. The subject was instructed to lift the wok and flip the wok with her non-dominant hand, based upon the speaker sound, to redistribute the soybeans and evenly heat them in the wok. The subject should flip the wok with the help of the culinary turning shovel lest the soybeans drop out of the wok. If the subject thought the wok was too heavy or too light, she could then adjust the amount of soybeans in the wok with her dominant hand holding the measuring glass according to her subjective perceived exertion until it represented the maximum acceptable weight she could flip for a formula without straining herself or becoming unusually tired, weakened, overheated, or out of breath (Ciriello et al., 1983). The frequency of flipping the wok was once per second. At the end of this step, the speaker said, "Please hold the culinary turning shovel".

The third step, which was "simulating the flipping wok task", lasted two minutes. Beginning with the adjusted and determined weight in the second step, the subject performs the task according to the instructions given by the speaker. Each working cycle lasted 15 seconds. The subject should lift the wok and shake it three times (one time per second) with her left hand, and then put it down. At this time, the subject should lift the culinary turning shovel with her right hand to perform the simulated food stir-frying task, first from right to left, then from left to right, and from front to back, altogether three times. After evenly stirring the soybeans in the wok, she then stops the task, waiting for the next cycle. After the subject does the task eight times, the experimental task is finished.

At the end of the flipping task, the experimenter weighs the weight of wok and soybeans, and asks the subject to report her fatigue and awareness of the various parts of her body on the subjective rating scale to collect the psychophysical perceived stress data. Figure 3 shows the experimental steps of the simulated wok flipping. 


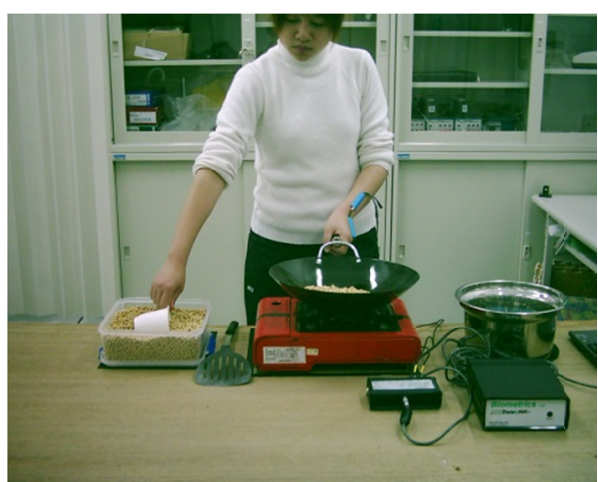

Step1: Establish a base weight

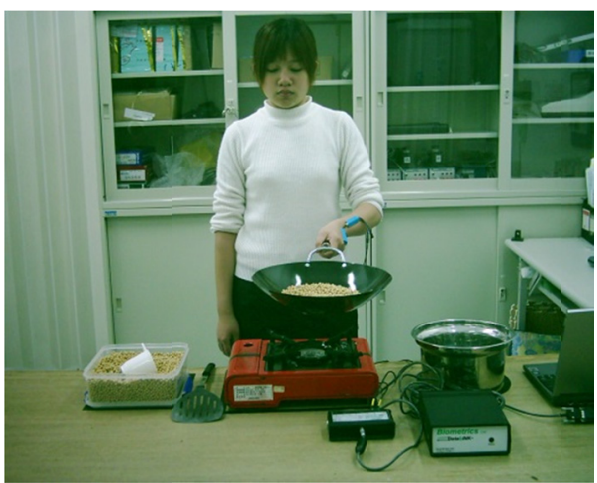

Step2: Determine MAWF

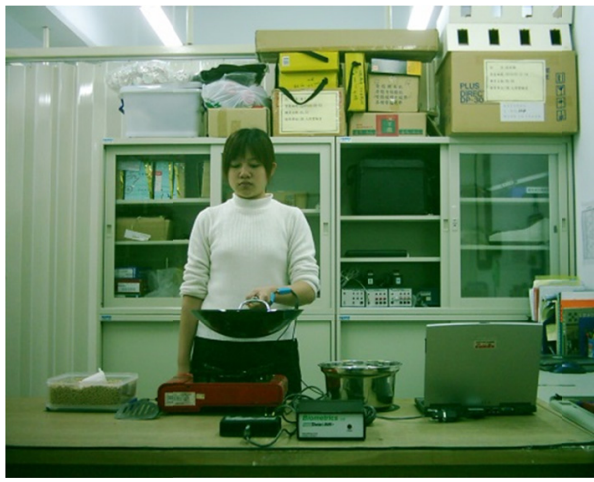

Step3: Simulated wok flipping task
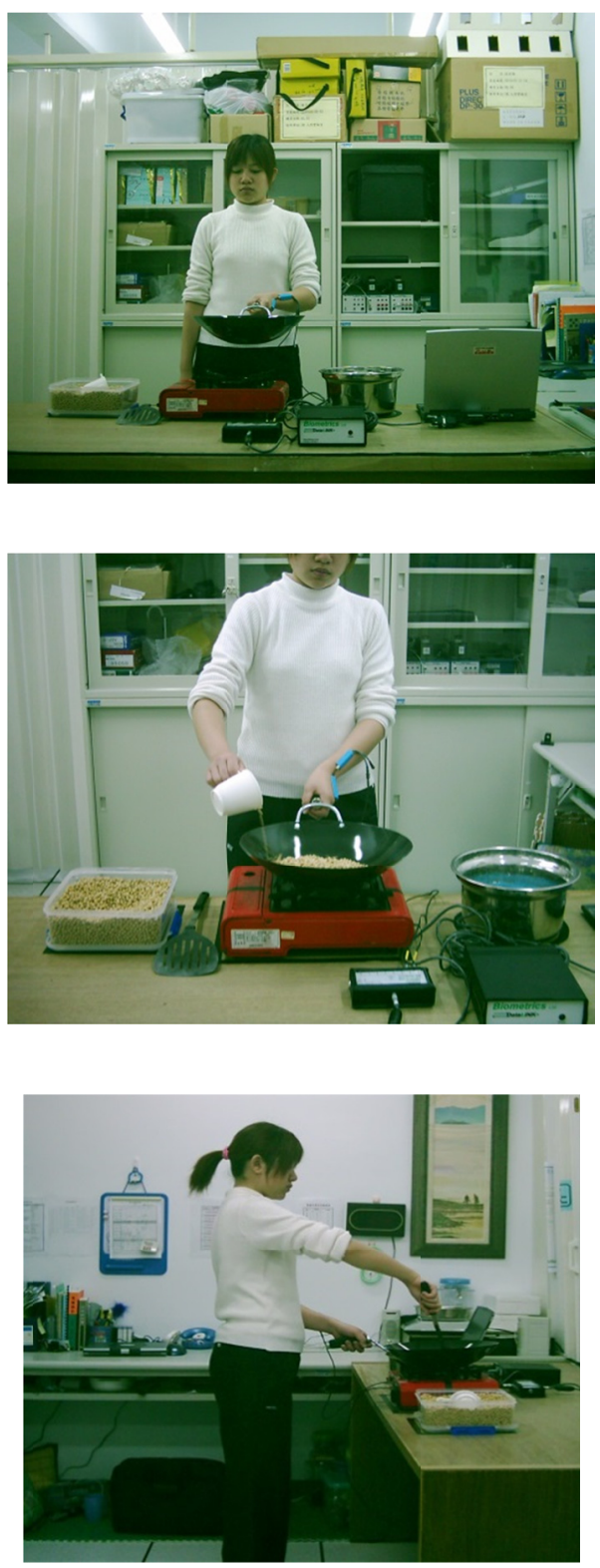

Figure 3. The experimental steps of the simulated wok flipping task

\subsection{Statistical Analysis}

The experimental data were stastisically analyzed, using the analysis of variance (ANOVA) method for three dependent variables: the maximum acceptable weight of wok flipping, wrist angle and the subjective rating. If a significant difference was noted, then Ducan multiple range tests were used for post hoc comparison. 
Table 1. Summary of the maximum acceptable weight of the flipping wok for the subjects

\begin{tabular}{cccc}
\hline \multirow{2}{*}{ Handle angle } & \multicolumn{3}{c}{ Wok size } \\
\cline { 2 - 4 } & $33 \mathrm{~cm}$ & $36 \mathrm{~cm}$ & $39 \mathrm{~cm}$ \\
\hline $25^{\circ}$ & $1584.96(334.07)$ & $1662.74(316.66)$ & $1640.99(273.28)$ \\
$10^{\circ}$ & $1652.24(357.29)$ & $1672.02(302.16)$ & $1677.49(332.34)$ \\
$-5^{\circ}$ & $1668.97(409.53)$ & $1707.28(377.46)$ & $1718.49(291.56)$ \\
$-20^{\circ}$ & $1701.85(406.80)$ & $1721.22(374.53)$ & $1761.20(383.08)$ \\
$-35^{\circ}$ & $1725.30(352.15)$ & $1797.64(371.64)$ & $1819.45(380.90)$ \\
\hline
\end{tabular}

Unit: g.

Table 2. ANOVA for subject's maximum acceptable weight of the flipping wok

\begin{tabular}{rrrrrr}
\hline \multicolumn{1}{c}{ Source } & df & \multicolumn{1}{c}{ S.S. } & \multicolumn{1}{c}{ M.S. } & F-value & P-value \\
\cline { 2 - 7 } Wok size $(\mathrm{W})$ & 2 & 108678.82 & 54339.41 & 3.47 & $0.0355^{*}$ \\
Handle angle $(\mathrm{H})$ & 4 & 480635.38 & 120158.84 & 7.67 & $<0.0001^{* *}$ \\
$\mathrm{~W} \times \mathrm{H}$ & 8 & 30672.41 & 3834.05 & 0.24 & 0.9809 \\
\cline { 2 - 7 }$<0.01, * \mathrm{p}<0.05, \alpha=0.05$. & 179 & 22747824.44 & & & \\
\cline { 2 - 7 }
\end{tabular}

Table 3. The Duncan multiple range test of the MAWF

\begin{tabular}{cccccc}
\hline Variables & Levels & Average & & Group & \\
\hline & $39 \mathrm{~cm}$ & 1723.53 & A & & \\
Wok size & $36 \mathrm{~cm}$ & 1712.18 & A & & \\
& $33 \mathrm{~cm}$ & 1666.66 & & B & \\
\hline & $-35^{\circ}$ & 1780.80 & A & & \\
& $-20^{\circ}$ & 1728.09 & A & B & \\
Handle angle & $-5^{\circ}$ & 1698.25 & & B & \\
& $10^{\circ}$ & 1667.25 & & B & C \\
& $25^{\circ}$ & 1629.56 & & & C \\
\hline
\end{tabular}

$\alpha=0.05$, unit: $\mathrm{g}$.

\section{Results}

\subsection{Maximum Acceptable Weight of Flipping}

The subjects performed the experimental task for five minutes to determine the maximum acceptable weight of flipping (MAWF). Table 1 shows the means and standard deviations of the MAWF.

As expected, the results of the analysis of variance (Table 2) show the wok size and the handle angle of the wok significantly affect the MAWF $(\mathrm{p}<0.05)$. As for the wok size, the Duncan multiple range test in Table 3 shows the MAWF produced by the $39 \mathrm{~cm}$ wok was significantly heavier than the $33 \mathrm{~cm}$ wok. There was no significant difference between the $39 \mathrm{~cm}$ and $36 \mathrm{~cm}$ wok. As for the handle angle, the MAWF produced by the $-35^{\circ}$ handle was significantly heavier than the $-5^{\circ}, 10^{\circ}$ and $25^{\circ}$ handles. There was no significant difference between the $-35^{\circ}$ and $-20^{\circ}$ handles. In addition, the difference between the $-20^{\circ},-5^{\circ}$ and $10^{\circ}$ handles was not statistically significant. The $25^{\circ}$ handle was the worst, but not significantly different from the $10^{\circ}$ handle.

\subsection{Wrist Angle}

Table 4 shows the means and standard deviations of the wrist angles for each deviation type. Table 5 and Table 6 show the results of the analysis of variance and Duncan multiple range test, respectively. 
Table 4. Summary of the mean wrist angle of the subjects for each deviation type

\begin{tabular}{|c|c|c|c|c|c|c|c|}
\hline \multirow{2}{*}{ Wok size } & \multirow{2}{*}{$\begin{array}{l}\text { Handle } \\
\text { angles }\end{array}$} & \multicolumn{2}{|c|}{ Ulnar deviation } & \multicolumn{2}{|c|}{ Palmar flexion } & \multicolumn{2}{|c|}{ Palmar extension } \\
\hline & & Mean & SD & Mean & SD & Mean & SD \\
\hline \multirow{5}{*}{$33 \mathrm{~cm}$} & $25^{\circ}$ & 33.65 & 6.17 & 9.51 & 5.34 & 4.40 & 4.54 \\
\hline & $10^{\circ}$ & 32.01 & 8.14 & 5.10 & 3.51 & 4.81 & 3.42 \\
\hline & $-5^{\circ}$ & 27.23 & 7.91 & 3.84 & 4.24 & 8.09 & 3.43 \\
\hline & $-20^{\circ}$ & 22.29 & 7.63 & 2.15 & 2.88 & 13.43 & 5.76 \\
\hline & $-35^{\circ}$ & 12.56 & 6.49 & 2.23 & 3.08 & 17.57 & 8.18 \\
\hline \multirow{5}{*}{$36 \mathrm{~cm}$} & $25^{\circ}$ & 34.34 & 7.19 & 12.48 & 7.09 & 1.98 & 2.72 \\
\hline & $10^{\circ}$ & 33.45 & 6.99 & 9.91 & 4.70 & 2.29 & 2.02 \\
\hline & $-5^{\circ}$ & 28.27 & 6.87 & 6.04 & 4.04 & 7.16 & 5.80 \\
\hline & $-20^{\circ}$ & 22.06 & 6.66 & 4.73 & 5.27 & 10.22 & 6.95 \\
\hline & $-35^{\circ}$ & 13.30 & 7.64 & 2.72 & 2.84 & 15.07 & 10.81 \\
\hline \multirow{5}{*}{$39 \mathrm{~cm}$} & $25^{\circ}$ & 35.59 & 6.81 & 16.90 & 11.01 & 2.19 & 3.74 \\
\hline & $10^{\circ}$ & 34.66 & 7.09 & 12.65 & 8.55 & 2.33 & 3.84 \\
\hline & $-5^{\circ}$ & 31.80 & 7.63 & 8.71 & 5.35 & 4.66 & 4.17 \\
\hline & $-20^{\circ}$ & 24.45 & 8.01 & 6.07 & 5.08 & 8.63 & 5.27 \\
\hline & $-35^{\circ}$ & 18.28 & 8.13 & 4.39 & 3.90 & 13.97 & 7.44 \\
\hline
\end{tabular}

Table 5. Summary of the ANOVA results of the wrist angle for each deviation type

\begin{tabular}{lccccccc} 
& \multicolumn{3}{c}{ Ulnar deviation } & \multicolumn{3}{c}{ Palmar flexion } & \multicolumn{3}{c}{ Palmar extension } \\
& F value & & F value & & F value & \\
\cline { 2 - 8 } & Wok size $(\mathrm{W})$ & 10.72 & $* *$ & 22.88 & $* *$ & 8.51 & $* *$ \\
Handle angle $(\mathrm{H})$ & 134.71 & $* *$ & 32.41 & $* *$ & 51.54 & $* *$ \\
$\mathrm{~W} \times \mathrm{H}$ & 0.63 & & 1.04 & & 0.30 & \\
\hline
\end{tabular}

$* \mathrm{P}<0.05, * * \mathrm{P}<0.01$.

Table 6. The Duncan multiple range test of the subject's wrist angle for each deviation type

\begin{tabular}{|c|c|c|c|c|c|c|c|c|c|}
\hline & \multicolumn{3}{|c|}{ Ulnar deviation } & \multicolumn{3}{|c|}{ Palmar flexion } & \multicolumn{3}{|c|}{ Palmar extension } \\
\hline & Level & Mean & Group & Level & Mean & Group & Level & Mean & Group \\
\hline & $39 \mathrm{~cm}$ & \multicolumn{2}{|c|}{$28.96 \mathrm{~A}$} & $39 \mathrm{~cm}$ & \multicolumn{2}{|c|}{$9.75 \mathrm{~A}$} & $33 \mathrm{~cm}$ & \multicolumn{2}{|c|}{$9.66 \mathrm{~A}$} \\
\hline \multirow[t]{4}{*}{ Wok size } & $36 \mathrm{~cm}$ & 26.28 & B & $36 \mathrm{~cm}$ & 7.17 & B & $36 \mathrm{~cm}$ & 7.35 & B \\
\hline & $33 \mathrm{~cm}$ & 25.55 & B & $33 \mathrm{~cm}$ & 4.57 & $\mathrm{C}$ & $39 \mathrm{~cm}$ & 6.36 & B \\
\hline & $25^{\circ}$ & 34.52 & & $25^{\circ}$ & $12.96 \mathrm{~A}$ & & $-35^{\circ}$ & 15.54 & \\
\hline & $10^{\circ}$ & 33.37 & & $10^{\circ}$ & 9.22 & B & $-20^{\circ}$ & 10.76 & $\mathrm{~B}$ \\
\hline \multirow[t]{3}{*}{ Handle angle } & $-5^{\circ}$ & 29.10 & $\mathrm{~B}$ & $-5^{\circ}$ & 6.20 & $\mathrm{C}$ & $-5^{\circ}$ & 6.64 & $\mathrm{C}$ \\
\hline & $-20^{\circ}$ & 22.94 & $\mathrm{C}$ & $-20^{\circ}$ & 4.32 & $\mathrm{CD}$ & $10^{\circ}$ & 3.14 & $\mathrm{D}$ \\
\hline & $-35^{\circ}$ & 14.71 & D & $-35^{\circ}$ & 3.11 & $\mathrm{D}$ & $25^{\circ}$ & 2.86 & $\mathrm{D}$ \\
\hline
\end{tabular}

\subsubsection{Ulnar Deviation}

Both the wok size and the handle angle significant affected the ulnar deviation (Table 5). As for the wok size, the Duncan multiple range test shows the $39 \mathrm{~cm}$ wok had the greatest ulnar deviation, while $36 \mathrm{~cm}$ and $33 \mathrm{~cm}$ woks 
did not differ between themselves. As to the handle angle, the $-35^{\circ}$ handle had the least ulnar deviation compared to the $-20^{\circ},-5^{\circ}, 10^{\circ}$ and $25^{\circ}$ handles; the $-20^{\circ}$ handle came next; the $-5^{\circ}$ handle came third; and the $10^{\circ}$ and $25^{\circ}$ handles had the greatest ulnar deviation.

\subsubsection{Radial Deviation}

Data analysis of the wrist angle shows there was no significant difference in the radial deviation of the subjects for each wok.

\subsubsection{Palmar Flexion}

The analysis of variance in Table 5 indicates both the wok size and handle angle significantly affected the wrist angle of palmar flexion. As for the wok size, the Duncan test results in Table 6 reveal the $33 \mathrm{~cm}$ wok had the least palmar flexion, the $36 \mathrm{~cm}$ wok came next; and the $39 \mathrm{~cm}$ wok had the greatest palmar flexion. For the handle angle, the $-35^{\circ}$ handle had the least palmar flexion compared to the $-20^{\circ},-5^{\circ}, 10^{\circ}$ and $25^{\circ}$ handle, but did not significantly differ from the $-20^{\circ}$ handle, and the $25^{\circ}$ handle had the greatest palmar flexion.

\subsubsection{Palmar Extension (Dorsiflexion)}

The ANOVA in Table 5 shows both wok size and handle angle significantly affected the palmar extension. As for the wok size, the subsequent Duncan test (Table 6) indicated the $39 \mathrm{~cm}$ wok had the least palmar extension, but did not significantly differ from the $36 \mathrm{~cm}$ wok, and the $33 \mathrm{~cm}$ wok had the greatest palmar extension. As to the handle angle, the $25^{\circ}$ handle had the least palmar extension compared to the $10^{\circ},-5^{\circ},-20^{\circ}$ and $-35^{\circ}$ handles, but did not significantly differ from the $10^{\circ}$ handle. The $-5^{\circ},-20^{\circ}$ and $-35^{\circ}$ handle were significantly different from one another, and the $-35^{\circ}$ handle had the greatest palmar extension.

Table 7. Summary of the means of the subjective rating*

\begin{tabular}{ccccccccc}
\hline & & Wrist & Arm & Shoulder & Grip & Exertion & Average & Overall \\
\hline & $25^{\circ}$ & 4.58 & 5.50 & 6.83 & 4.25 & 4.17 & 5.086 & \\
33 & $10^{\circ}$ & 4.50 & 6.00 & 7.25 & 6.58 & 5.92 & 6.050 & \\
$\mathrm{~cm}$ & $-5^{\circ}$ & 4.92 & 6.25 & 6.92 & 6.00 & 5.75 & 5.968 & 6.00 \\
& $-20^{\circ}$ & 5.75 & 6.08 & 7.75 & 6.67 & 6.33 & 6.516 & \\
& $-35^{\circ}$ & 5.75 & 5.83 & 7.25 & 6.50 & 6.58 & 6.382 & \\
\hline & $25^{\circ}$ & 3.75 & 4.92 & 7.25 & 4.25 & 4.17 & 4.865 & \\
36 & $10^{\circ}$ & 4.00 & 5.92 & 6.92 & 4.58 & 4.50 & 5.184 & \\
$\mathrm{~cm}$ & $-5^{\circ}$ & 4.50 & 5.17 & 7.25 & 4.83 & 5.08 & 5.366 & 5.32 \\
& $-20^{\circ}$ & 4.67 & 5.25 & 6.83 & 5.42 & 5.50 & 5.534 & \\
& $-35^{\circ}$ & 5.25 & 5.25 & 6.75 & 5.42 & 5.58 & 5.650 & \\
\hline & $25^{\circ}$ & 3.08 & 4.67 & 6.58 & 3.00 & 2.67 & 4.000 & \\
39 & $10^{\circ}$ & 3.17 & 5.67 & 6.92 & 3.67 & 3.00 & 4.486 & \\
$\mathrm{~cm}$ & $-5^{\circ}$ & 3.17 & 4.58 & 6.67 & 3.17 & 3.00 & 4.118 & 4.37 \\
& $-20^{\circ}$ & 3.67 & 4.42 & 6.42 & 4.08 & 3.92 & 4.502 & \\
& $-35^{\circ}$ & 3.92 & 5.08 & 6.42 & 4.08 & 4.25 & 4.750 & \\
\hline
\end{tabular}

*the higher the score, the better.

Table 8. Summary of the ANOVA results of the subjective rating

\begin{tabular}{|c|c|c|c|c|c|c|c|c|c|c|}
\hline \multirow{3}{*}{$\begin{array}{l}\text { Source } \\
\text { Wok size }(\mathrm{W})\end{array}$} & \multirow{2}{*}{\multicolumn{2}{|c|}{$\begin{array}{c}\text { Wrist } \\
\text { F-value }\end{array}$}} & \multirow{2}{*}{\multicolumn{2}{|c|}{$\begin{array}{c}\text { Arm } \\
\text { F-value }\end{array}$}} & \multirow{2}{*}{\multicolumn{2}{|c|}{$\begin{array}{c}\text { Shoulder } \\
\text { F-value } \\
\end{array}$}} & \multirow{2}{*}{\multicolumn{2}{|c|}{$\begin{array}{c}\text { Grip } \\
\text { F-value }\end{array}$}} & \multirow{2}{*}{\multicolumn{2}{|c|}{$\begin{array}{c}\text { Exertion } \\
\text { F-value } \\
\end{array}$}} \\
\hline & & & & & & & & & & \\
\hline & 26.51 & $* *$ & 9.77 & $* *$ & 4.39 & * & 34.28 & $* *$ & 34.10 & ** \\
\hline Handle Angle(H) & 5.59 & $* *$ & 1.96 & * & 0.22 & & 5.70 & $* *$ & 7.02 & ** \\
\hline $\mathrm{W} \times \mathrm{H}$ & 0.31 & & 0.66 & & 0.97 & & 0.82 & & 0.50 & \\
\hline
\end{tabular}

${ }_{* *} \mathrm{p}<0.01,{ }^{*} \mathrm{p}<0.05, \alpha=0.05$ 


\subsection{Subjective Rating}

To rate the subject's subjective feeling and her perceived exertion, after each test, the subject was asked to fill out a semantic differential scale. The scale contained five adjective pairs: wrist aching - wrist not aching, arm aching - arm not aching, shoulder aching - shoulder not aching, gripping easily - gripping difficulty, and exerting easily - exerting difficulty. Each pair had an unmarked scale from one (aching or difficulty) to nine (not aching or easy). The higher the scores on the scale, the less fatigued the subject felt, or the better the design. Table 7 summarizes the means and standard deviations of the subject's rating. Table 8 and Table 9 show the summary of the ANOVA results and Duncan multiple range test of the subjective rating, respectively.

Table 9. Summary of the Duncan Test of the subjective rating

\begin{tabular}{|c|c|c|c|c|c|c|}
\hline & Variables & Levels & Average & \multicolumn{3}{|c|}{ Grouping } \\
\hline \multirow[t]{8}{*}{ Wrists } & Wok size & $33 \mathrm{~cm}$ & 5.10 & $\mathrm{~A}$ & \multirow{3}{*}{ B } & \\
\hline & & $36 \mathrm{~cm}$ & 4.43 & & & \\
\hline & & $39 \mathrm{~cm}$ & 3.40 & & & C \\
\hline & Handle angle & $-35^{\circ}$ & 4.97 & A & & \\
\hline & & $-20^{\circ}$ & 4.69 & A & B & \\
\hline & & $-5^{\circ}$ & 4.19 & & B & $\mathrm{C}$ \\
\hline & & $10^{\circ}$ & 3.89 & & & $\mathrm{C}$ \\
\hline & & $25^{\circ}$ & 3.81 & & & $\mathrm{C}$ \\
\hline \multirow[t]{8}{*}{ Arms } & Wok size & $33 \mathrm{~cm}$ & 5.93 & A & & \\
\hline & & $36 \mathrm{~cm}$ & 5.30 & & B & \\
\hline & & $39 \mathrm{~cm}$ & 4.88 & & B & \\
\hline & Handle angle & $10^{\circ}$ & 5.86 & A & & \\
\hline & & $-35^{\circ}$ & 5.39 & A & B & \\
\hline & & $-20^{\circ}$ & 5.33 & A & B & \\
\hline & & $-5^{\circ}$ & 5.25 & A & B & \\
\hline & & $25^{\circ}$ & 5.03 & & B & \\
\hline \multirow[t]{8}{*}{ Shoulders } & Wok size & $33 \mathrm{~cm}$ & 7.20 & A & & \\
\hline & & $36 \mathrm{~cm}$ & 7.00 & A & B & \\
\hline & & $39 \mathrm{~cm}$ & 6.60 & & B & \\
\hline & Handle angle & $10^{\circ}$ & 7.02 & A & & \\
\hline & & $-20^{\circ}$ & 7.00 & A & & \\
\hline & & $-5^{\circ}$ & 6.94 & A & & \\
\hline & & $25^{\circ}$ & 6.89 & A & & \\
\hline & & $-35^{\circ}$ & 6.81 & A & & \\
\hline \multirow[t]{8}{*}{ Grip } & Wok size & $33 \mathrm{~cm}$ & 6.00 & $\mathrm{~A}$ & & \\
\hline & & $36 \mathrm{~cm}$ & 4.90 & & B & \\
\hline & & $39 \mathrm{~cm}$ & 3.60 & & & $\mathrm{C}$ \\
\hline & Handle angle & $-20^{\circ}$ & 5.39 & A & & \\
\hline & & $-35^{\circ}$ & 5.33 & A & & \\
\hline & & $10^{\circ}$ & 4.94 & A & & \\
\hline & & $-5^{\circ}$ & 4.67 & A & & \\
\hline & & $25^{\circ}$ & 3.83 & & B & \\
\hline \multirow[t]{8}{*}{ Exertion } & Wok size & $33 \mathrm{~cm}$ & 5.75 & A & & \\
\hline & & $36 \mathrm{~cm}$ & 4.97 & & B & \\
\hline & & $39 \mathrm{~cm}$ & 3.36 & & & $\mathrm{C}$ \\
\hline & Handle angle & $-35^{\circ}$ & 5.47 & A & & \\
\hline & & $-20^{\circ}$ & 5.25 & A & B & \\
\hline & & $-5^{\circ}$ & 4.61 & & B & \\
\hline & & $10^{\circ}$ & 4.47 & & B & \\
\hline & & $25^{\circ}$ & 3.67 & & & $\mathrm{C}$ \\
\hline
\end{tabular}

\subsubsection{Wrist, Arm and Shoulder Ache}

Both the wok size and the handle angle significantly affected the subjective rating for the subject's wrist aching (Table 8). With the wok size, significantly less ache in the wrist was reported in the $33 \mathrm{~cm}$ wok than the $36 \mathrm{~cm}$ and $39 \mathrm{~cm}$ wok, and significantly less ache in the wrist was reported in the $36 \mathrm{~cm}$ wok than the $39 \mathrm{~cm}$ wok. With 
the handle angle, significantly less ache in the wrist was reported in the $-35^{\circ}$ handle than the $-5^{\circ}, 10^{\circ}$ and $25^{\circ}$ handles, while there no significant reported difference from the $-20^{\circ}$ handle (Table 9).

The wok size significantly affected the subjective rating for the subjects' shoulder aching (Table 5). As shown in Table 8 , significantly less ache in the shoulder was reported in the $33 \mathrm{~cm}$ wok than the $39 \mathrm{~cm}$ wok, while there was no significant reported difference from the $36 \mathrm{~cm}$ wok. There was no significant difference reported in shoulder ache between the handle angles (Table 9).

\subsubsection{Ease of Grip and Exertion}

Both the wok size and the handle angle significantly affected the subjective rating of the subject's ease of grip (Table 8). With the wok size, significantly more ease of grip was reported in the $33 \mathrm{~cm}$ wok than the $36 \mathrm{~cm}$ and $39 \mathrm{~cm}$ woks, and significantly more ease of grip was also reported in the $36 \mathrm{~cm}$ wok than the $39 \mathrm{~cm}$ wok. With the handle angle, significantly more ease of grip was reported in the $-20^{\circ}$ handle than the $25^{\circ}$ handle, and there was no difference between the $-20^{\circ},-35^{\circ}, 10^{\circ}$ and $-5^{\circ}$ handles (Table 9 ).

Both the wok size and handle angle significantly affected the subjective rating of exertion easiness (Table 8). With the wok size, significantly more exertion ease was reported in the $33 \mathrm{~cm}$ wok than the $36 \mathrm{~cm}$ and $39 \mathrm{~cm}$ woks, and significantly more exertion ease was reported in the $36 \mathrm{~cm}$ wok than the $39 \mathrm{~cm}$ wok. With the handle angle, significantly more exertion ease was reported in the $-35^{\circ}$ handle than the $-5^{\circ}, 10^{\circ}$ and $25^{\circ}$ handles, and there was no difference between the $-20^{\circ},-5^{\circ}$ and $10^{\circ}$ handles. Significantly less ease of exertion was reported in the $25^{\circ}$ handle (Table 9).

\section{Discussion}

There are numerous factors influencing the comfort and performance of the cooks. This study focused attention on the effect of the wok size and handle angle on the MAWF, wrist angle and subjective rating. The results show both wok size and handle angle significantly affect these criteria. The interaction effects among all responses for the wok size and handle angle were not significant. Therefore, the ideal wok size and handle angle can be selected independently from each other without considering the combined effect of these two factors.

\subsection{Effect of the Wok Size}

\subsubsection{Maximum Acceptable Weight of Flipping}

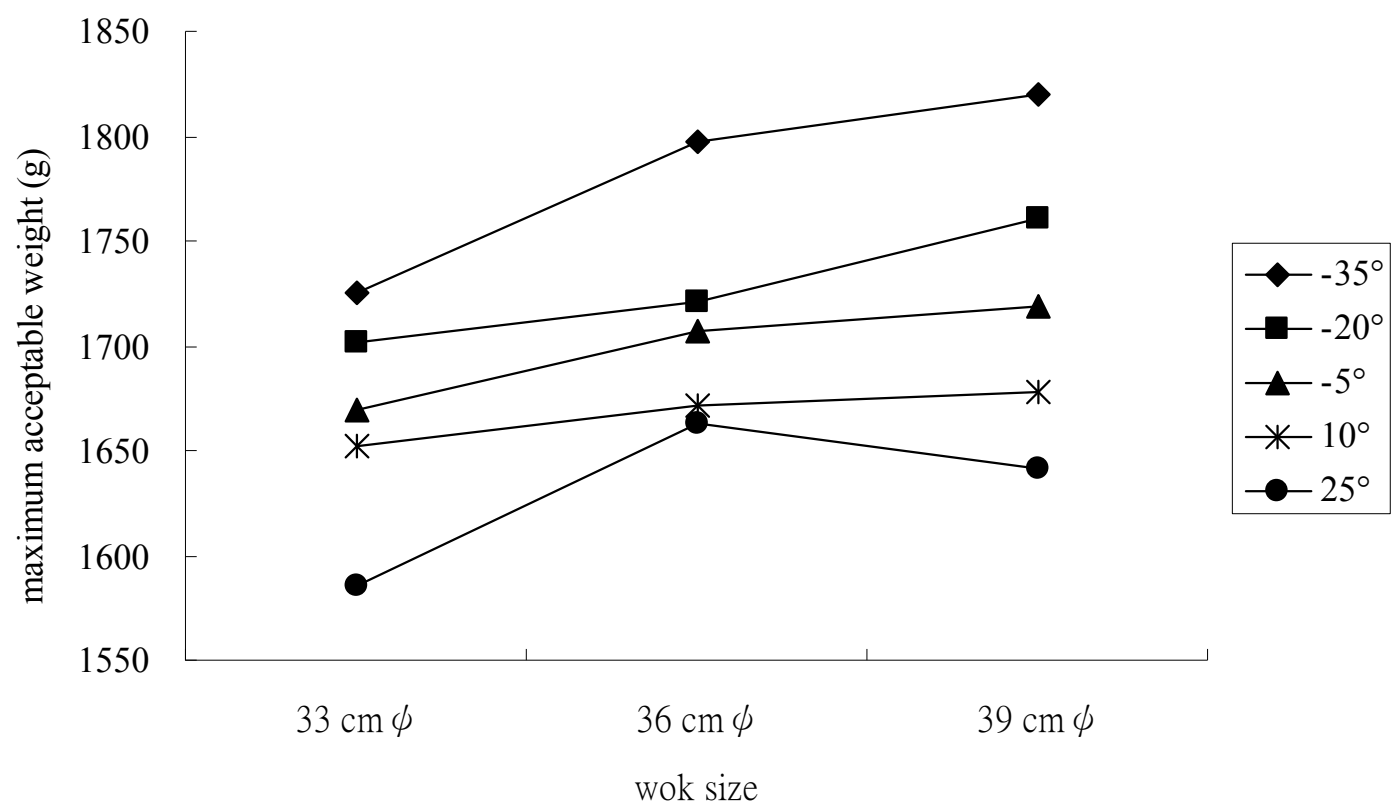

Figure 4. Effect of wok size on the MAWF

As shown in Figure 4, the subject's MAWF increased with the wok size. This finding was consistent with Wu et al. (2011). Based upon biomechanical mechanisms, the center of gravity of a larger wok would be relatively far away from the exertion point of wrist which in turn caused low maximum acceptable weight of flipping. These conflicting results may be caused by the effect of the size-weight illusion (Luczak \& Ge, 1989). In other words, the subjects perceive larger woks to be lighter than smaller woks of the same mass, and lift greater masses. This 
phenomenon is very important because any decrease in perceived heaviness accompanying larger woks could lead the subjects exceeding the limits of safety (Naylor \& Amazeen, 2004).

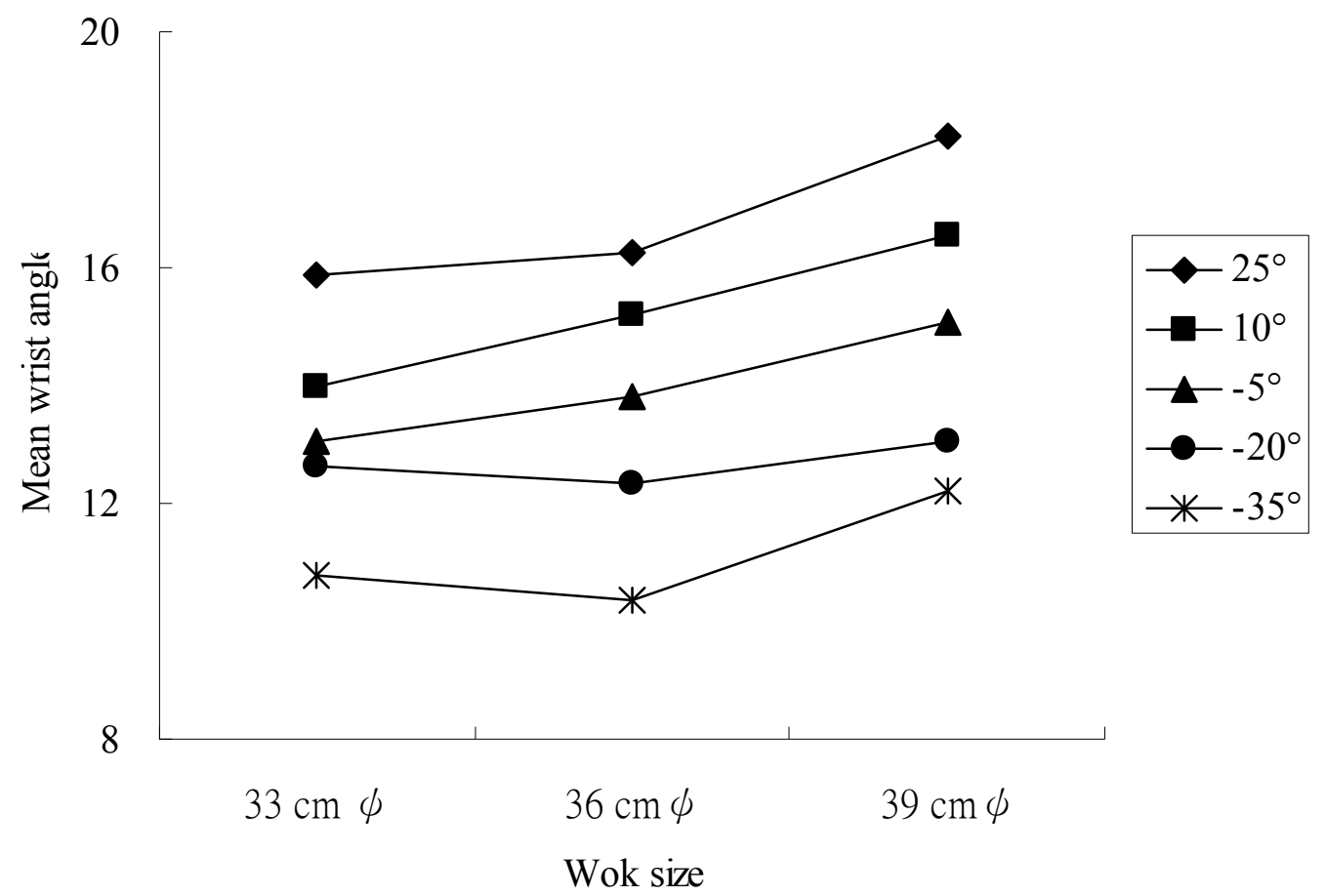

Figure 5. Effect of wok size on the mean wrist angle for all deviation types

\subsubsection{Wrist Angle}

Figure 5 show the effect of the wok size on the overall mean wrist angle for all three deviation types for the subjects' wrist angle. The $39 \mathrm{~cm}$ wok caused a greater wrist angle than the $33 \mathrm{~cm}$ and $36 \mathrm{~cm}$ woks. In general, the $33 \mathrm{~cm}$ wok decreased the wrist angle significantly, especially the ulnar deviation and palmar flexion. This decrese in wrist angle for small woks may be primarily due to increased MAWF of larger woks. As mentioned by McGorry et al. (2014), carpal tunnel pressure (CTP) increase during wrist extention when employing a pinch or power grip. Therefore, with respect to wrist angle, the small wok is superior to the larger wok.

\subsubsection{Subjective Rating}

A wok with a bigger diameter is usually quite heavy and its center of gravity is far from the hand. When a subject does the flipping task, he will be apt to feel fatigue in his wrists, arms and shoulders. It will also be difficult for him to hold, and exert with the wok. Because of his difficulty in exertion with the wok, some uncoordinated postures and movements will appear in his hands, causing low wok assessment scores. As shown in Table 7, the $33 \mathrm{~cm}$ wok was reported the highest in overall subjective rating (6.00), while the $39 \mathrm{~cm}$ wok was reported the lowest (4.37). This may be caused by the overexertion of the larger MAWF produced by the size-weight illusion.

\subsubsection{Overall Comparison}

Figure 6 shows the data for the three criteria used in this study. The criterion scales in Figure 6 were based upon relative percentage and converted into fairly arbitrary values respectively. Only "desirable" and "undesirable" attributes were indicated (Hsu \& Wu, 1991, Wu \& Hsieh, 2002). It can be seen the $33 \mathrm{~cm}$ wok was the best in the wrist angle and subjective rating. However, when considering the size-weight illusion effect, the $33 \mathrm{~cm}$, wok was better than the $39 \mathrm{~cm}$ wok. Further comprehensive comparison of the three criteria in the Table 10 also verified the $33 \mathrm{~cm}$ wok was better than the $39 \mathrm{~cm}$ wok and $36 \mathrm{~cm}$ woks. 


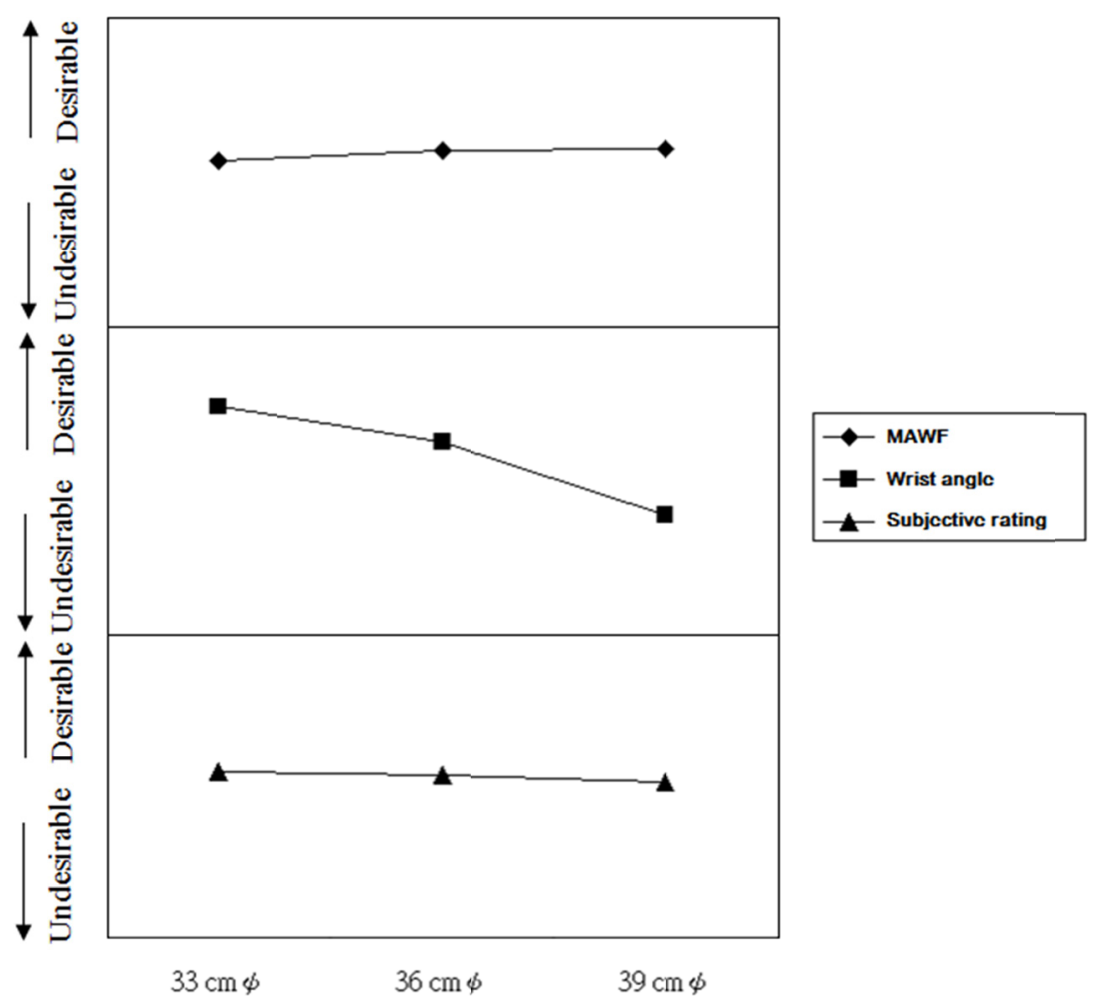

Figure 6. Comprehensive effect of the diameter of the wok

Table 10. Comprehensive comparison of the four criteria used to evaluate the woks

\begin{tabular}{rcccc}
\hline & MAWF $^{*}$ & Wrist angle & Subjective rating & Total \\
\hline Wok size & & & & \\
$33 \mathrm{~cm}$ & +1 & +1 & +1 & +3 \\
$36 \mathrm{~cm}$ & 0 & 0 & 0 & 0 \\
$39 \mathrm{~cm}$ & -1 & -1 & -1 & -3
\end{tabular}

Handle angle

\begin{tabular}{ccccc}
$25^{\circ}$ & -1 & -1 & -1 & -3 \\
$10^{\circ}$ & -1 & 0 & 0 & -1 \\
$-5^{\circ}$ & 0 & 0 & 0 & 0 \\
$-20^{\circ}$ & +1 & 0 & 0 & +1 \\
$-35^{\circ}$ & +1 & +1 & +1 & +3 \\
\hline
\end{tabular}

Note :

The highest level of Duncan's multiple range test, the wok(s) obtains +1 .

The lowest level of Duncan's multiple range test, the wok(s) obtains -1 .

Considering the effect of the size-weight illusion on the MAWF, the $33 \mathrm{~cm}$ was the best, and the $39 \mathrm{~cm}$ wok was the worst.

\subsection{Effects of the Handle Angle of a Wok}

\subsubsection{Maximum Acceptable Weight of Flipping}

In the action of the flipping task, the more the wok handle bends upward, the more serious the wrist deviation and flexion. Under this circumstance, if a subject wants to flip the food in the wok by exertion of his arms, his wrists will bear too much burden. Figure 7 shows the $-35^{\circ}$ handle is best, the $25^{\circ}$ handle is worst, and the MAWF increases in sequence from $25^{\circ}$ to $-35^{\circ}$. This is because, when a wok handle with a downward angle is used, the 
user can keep his wrist neutral and avoid lifting his arm and shoulder. This improves the subject's MAWF. This finding was consistent with previous studies (Wu et al., 2011; Hsu \& Chen, 1999).

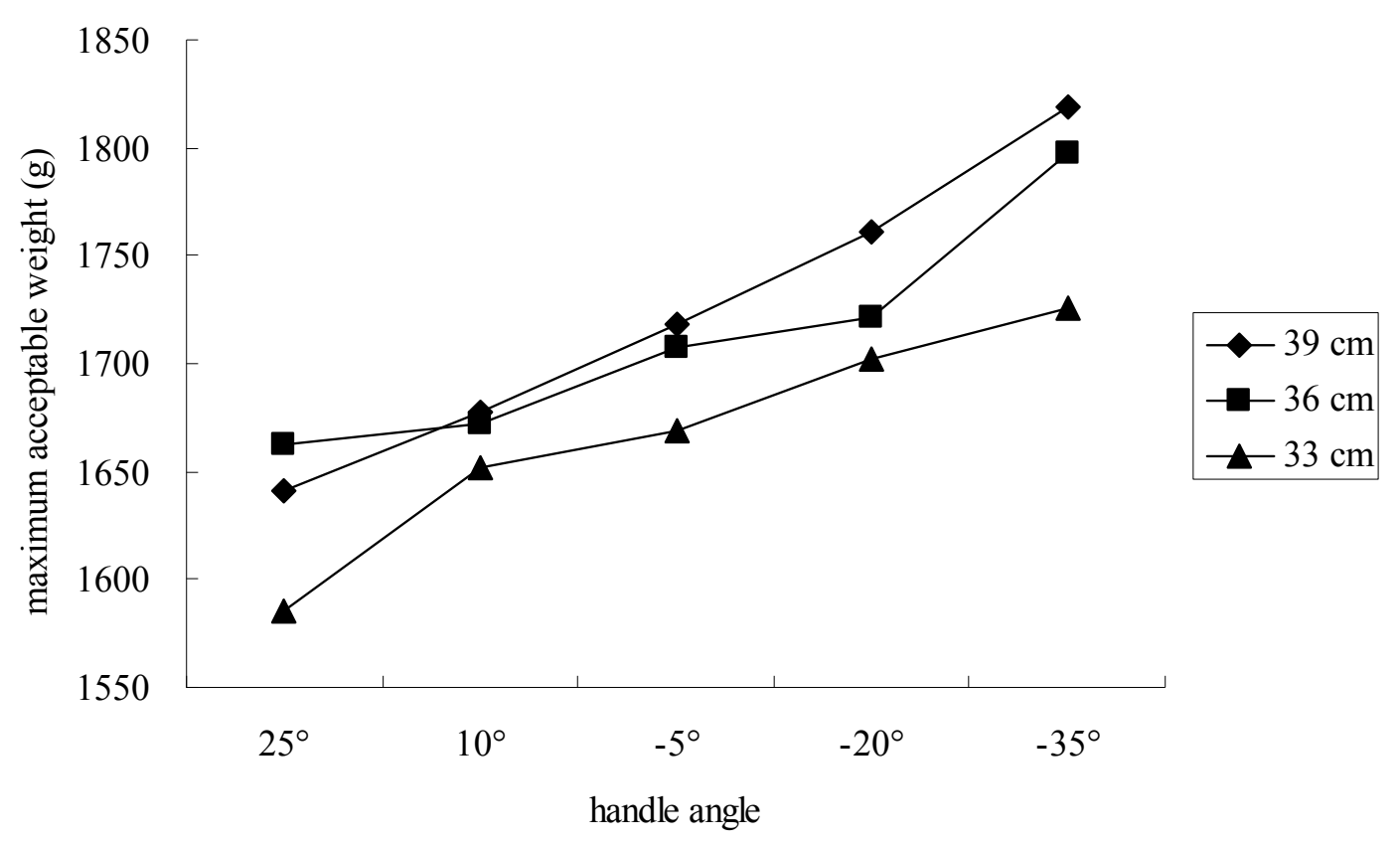

Figure 7. Effect of the handle angle of the wok on the MAWF

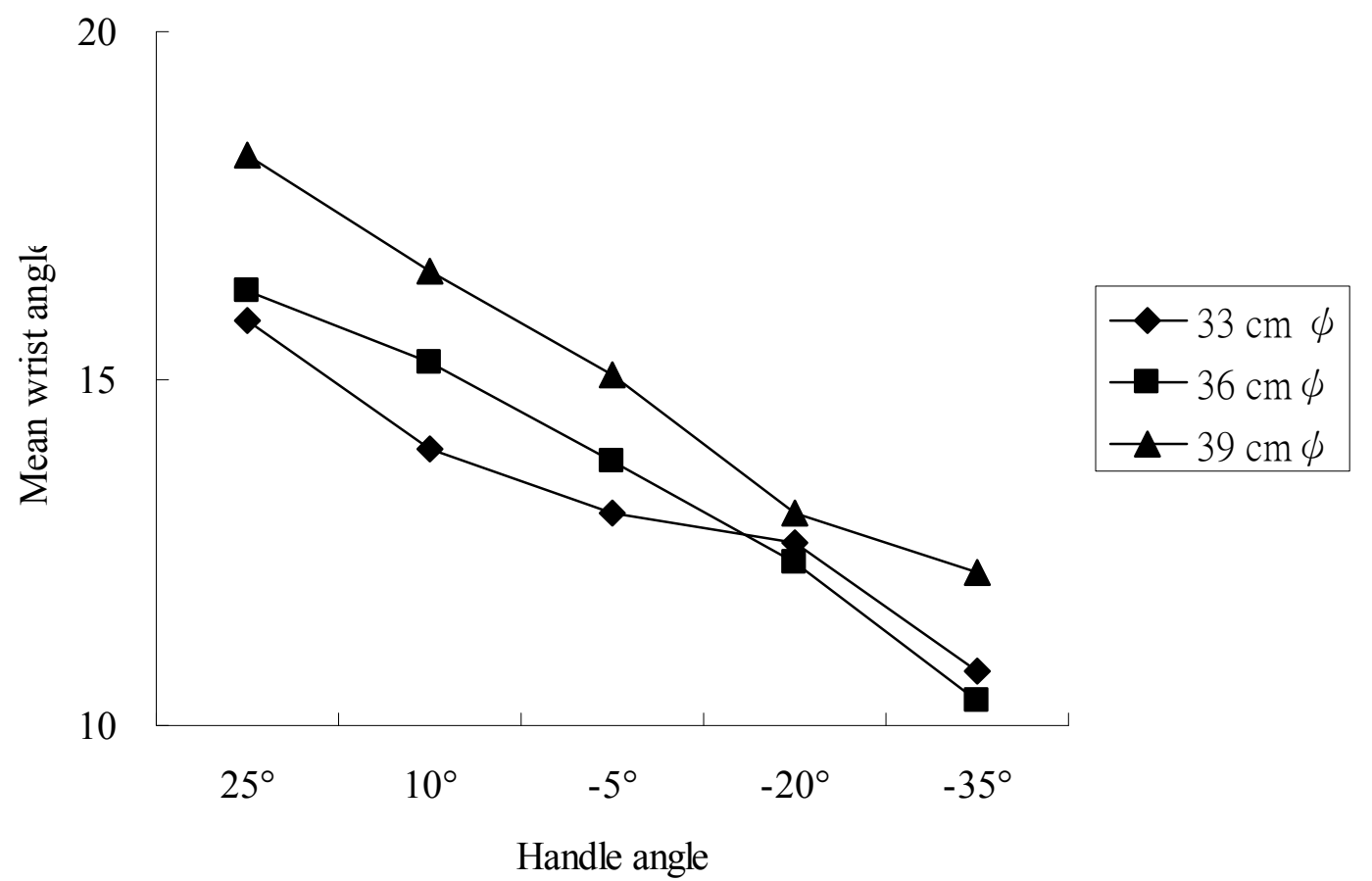

Figure 8. Effect of the handle angle of the wok on the mean wrist angle for all deviation types

\subsubsection{Wrist Angle}

Figure 8 shows the effect of the handle angle of the wok on the overall mean wrist angle for all three deviation types for the subjects' wrist angle. As can be seen, the conventional woks $\left(25^{\circ}\right.$ and $\left.10^{\circ}\right)$ caused a greater wrist angle, and the bent-handled woks $\left(-5^{\circ},-20^{\circ}\right.$ and $\left.-35^{\circ}\right)$ decreased the wrist angle. Carey and Gallwey (2002) 
revealed extreme flexion caused higher discomfort than other simple types of deviation, and the combination of palmar flexion and ulnar deviation resulted in higher discomfort than the other types of combined deviation. The results of the study in Table 6 verified bent-handled woks could effectively and significantly decrease the palmar flexion with ulnar deviation.

\subsubsection{Subjective Rating}

The wok handle angle has a significant effect on the wrist, grip, and exertion in the subjective rating. In the flipping task action, the wok with a downward handle can hold the user's wrists in a neutral posture instead of a posture with ulnar deviation. As mentioned by Werner et al. (1997), the angle of the wrist during grip-type exertions directly affects the amount of intrawrist supporting forces acting normal to the direction of the tendons and their synovial. Because of this relationship, it is proposed the wrist be kept relatively straight during forceful gripping, to avoid large intrawrist forces. Table 7 shows the $-35^{\circ}$ handle was the highest, the $-20^{\circ}$ handle was the second highest, which is better than the $10^{\circ}$ handle, while the $25^{\circ}$ handle was the lowest. In other words, the subjects rated the bent-handled woks better than the conventional straight-handle woks.

\subsubsection{Overall Comparison}

Figure 9 demonstrates the data for criteria relating to the handle angle of a wok. The criterion scales in Figure 9 are the same as Figure 6, based upon relative percentage and converted to "desira ble" and "undesirable" attributes. Figure 9 , the $-35^{\circ}$ handle was the best among MAWF, wrist angle, and the subjective rating. Further quantitative comparison from Table 10 also revealed the $-35^{\circ}$ handle was best, and the bent-handled wok was better than the straight-handled wok.

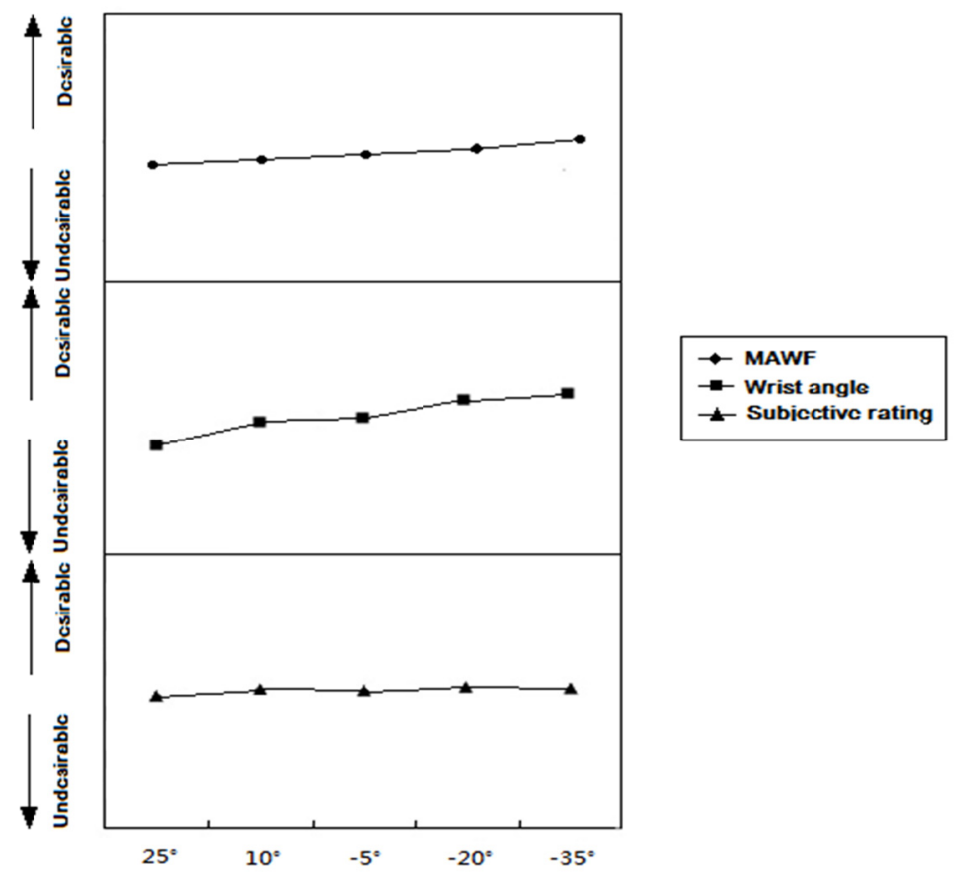

Figure 9. Comprehensive effects of the handle angles of the wok

\subsection{Comparison with Previous Study}

Table 11 presents the comparison of the optimal wok sizes and handle angles of a wok according to three criteria in this study with the data of Wu et al. (2011) concerning the wok flipping task. As observed, for the wok size, the results from this study were consistent with $\mathrm{Wu}$ et al. (2011), the small wok (33cm and $36 \mathrm{~cm}$ woks for females and males, respectively) performed best. For the handle angle, the best bending angle in this study was the $-35^{\circ}$ angle. This result is somewhat different from the optimum angle $\left(-5^{\circ} \sim 35^{\circ}\right)$ in Wu et al. (2011). This may be attributed to the different criteria used in both study. Based upon the subject's preference ranking, a wok with $-5^{\circ}$ handle angle was optimum in $\mathrm{Wu}$ et al. (2011). However, according to the objective criterion measurement of wrist angle, a wok with $-35^{\circ}$ handle angle was best in the present study. Overall, a small wok with an ergonomic bent handle is ideal for cooks when performing the flipping task. 
Table 11. Comparison with previous study by Wu et al. (2011)

\begin{tabular}{|c|c|c|c|c|c|c|}
\hline & Variables & MAWF & $\begin{array}{l}\text { Subjective } \\
\text { ranking }\end{array}$ & $\begin{array}{l}\text { Subjective } \\
\text { ranking }\end{array}$ & $\begin{array}{l}\text { Wrist } \\
\text { angle }\end{array}$ & $\begin{array}{c}\text { Total } \\
\text { (optimum) }\end{array}$ \\
\hline \multirow[t]{2}{*}{ Present study } & Wok size & $39 \mathrm{~cm}$ & $33 \mathrm{~cm}$ & - & $33 \mathrm{~cm}$ & $33 \mathrm{~cm}$ \\
\hline & $\begin{array}{c}\text { Handle } \\
\text { angle }\end{array}$ & $-35^{\circ}$ & $-35^{\circ}$ & - & $-35^{\circ}$ & $-35^{\circ}$ \\
\hline \multirow{2}{*}{$\begin{array}{l}\mathrm{Wu} \text { et al. } \\
(2011)\end{array}$} & Wok size & $42 \mathrm{~cm}$ & $36 \mathrm{~cm}$ & $36 \mathrm{~cm}$ & - & $36 \mathrm{~cm}$ \\
\hline & $\begin{array}{c}\text { Handle } \\
\text { angle }\end{array}$ & $-35^{\circ}$ & $-20^{\circ}$ & $-5^{\circ}$ & - & $-5^{\circ} \sim 35^{\circ}$ \\
\hline
\end{tabular}

Note: Three wok sizes $(36 \mathrm{~cm}, 39 \mathrm{~cm}$, and $42 \mathrm{~cm})$ were used by Wu et al. (2011)

\section{Conclusions}

For the purpose of decreasing the awkward posture and reduce the physical load on the female cooks, the effect of wok size and handle angle on the maximum acceptable weight of flipping,wrist angle and the subjective rating was investigated. The results showed wok size significantly affects MAWF, wrist angle and subjective rating. Considering the size-weight illusion effect on the MAWF, the $33 \mathrm{~cm}$ wok was the best. Wok handle angle also significantly affected MAWF, wrist angle and subjective rating. The $-35^{\circ}$ handle angle was the best. In addition, this paper confirmed the finding of $\mathrm{Wu}$ et al. (2011), the effect of the size-weight illusion on MAWF was significant in flipping tasks. In general, this study concluded the $33 \mathrm{~cm}$ diameter wok with a $-35^{\circ}$ bent-handle was ideal for female cooks using stir-frying dishes. However, since this experiment of wok flipping task was performed in a laboratory and the subjects of this study were all young cooks, it is not clear these results apply to elderly cooks. Therefore, it is suggested that a field experiment with young and elderly cooks should be conducted.

\section{References}

Armstrong, T. J., Foulke, J. A., Joseph, B. S., \& Goldstein, S. A. (1982). Investigation of cumulative trauma disorders in a poultry processing plant. America Industrial Hygiene Association Journal, 43(2), 103-116. http://dx.doi.org/10.1080/15298668291409433

Armstrong, T. J., Radwin, R. G., Hansen, D. J., \& Kennedy, K. W. (1986). Repetitive trauma disorders: job evaluation and design. Human Factors, 28, 325-336.

Aghazadeh, F., \& Mital, A. (1987). Injuries due to handtools: Results of a questionnaire. Applied Ergonomics, 18, 273-278. http://dx.doi.org/10.1016/0003-6870(87)90134-7

Buckle, P. W., \& Devereux, J. J. (2002). The nature of eork-related neck and upper limb musculoskeletal disorders. Applied Ergonomics, 33, 207-217. http://dx.doi.org/10.1016/S0003-6870(02)00014-5

Carey, E. J., \& Gallwey, T. J. (2002). Effects of wrist posture, pace and exertion on discomfort. International Journal of Industrial Ergonomics, 29, 85-94. http://dx.doi.org/10.1016/S0169-8141(01)00053-1

Chang, S. R., Park, S., \& Freivslds, A. (1999). Ergonomic evaluation of the effects of handle types on garden tools. International Journal of Industrial Ergonomics, 24, 99-105. http://dx.doi.org/10.1016/S0169-8141(98)00091-2

Ciriello, V. M., \& Snook, S. H. (1983) A study of size, distance, height, and frequency effects on manual material handling tasks. Human Factors, 25(5), 473-483.

Eksioglu, M. (2006). Optimal work-rest cycles for an isometric intermittent gripping task as a function of force, posture and grip span. Ergonomics, 49(2), 180-201. http://dx.doi.org/10.1080/00140130500465527

Hsu, S. H., \& Chen, Y. H. (1999). Evaluation of bent-handled files. International Journal of Industrial Ergonomics, 25, 1-10. http://dx.doi.org/10.1016/S0169-8141(98)00071-7

Hsu, S. H., \& Wu, S. P. (1991). An investigation for determining the optimum length of the chopsticks. Applied Ergonomics, 22(6), 395-440. http://dx.doi.org/10.1016/0003-6870(91)90082-S

Hsu, S. H., Wu, S. P., \& Peng, Y. (1994). The optimum lift angle for the culinary spatula (turning shovel). Ergonomics, 37(2), 325-332. http://dx.doi.org/10.1080/00140139408963649 
Konz, S. (1986). Bent handle hammer. Human Factors, 28(3), 317-323.

Lewis, W. G. and Narayan, C. V., 1993, "Design and sizing of ergonomic handles for hand tools", Applied Ergonomics, 24(5), 351-356. http://dx.doi.org/10.1016/0003-6870(93)90074-J

Li, K. W., 2002, "Ergonomic design and evaluation of wire-tying hand tools", International Journal of Industrial Ergonomics, 30, 149-161. http://dx.doi.org/10.1016/S0169-8141(02)00097-5

Lintula, M. and Nevala, N., 2006, "Ergonomics and the usability of mechanical single-channel liquid dosage pipettes", International Journal of Industrial Ergonomics, 36, 257-263. http://dx.doi.org/10.1016/j.ergon.2005.06.011

Malchaire, J. B., Cock, N. A., \& Robert, A. R. (1996). Prevalence of musculoskeletal disorders at the wrist as a function of angles, forces, repetitiveness and movement velocities. Scandinavian Journal of Work, Environment \& Health, 22, 176-181. http://dx.doi.org/10.5271/sjweh.128

McGorry, R. W., \& Lin, J. H. (2007). Power grip strength as a function of tool handle orientation and location. Ergonomics, 50(9), 1392-1403. http://dx.doi.org/10.1080/00140130701340115

McGorry, R. W., Fallentin, N., Andersen, J. H., Keir, P. J., Hansen, T. B., Pransky, G., \& Lin, J. H. (2014). Effect of grip type, wrist motion, and resistance level on pressures within the carpal tunnel of normal wrists. Journal of Orthopaedic Research, 32(4), 524-530. http://dx.doi.org/10.1002/jor.22571

Mital, A., Pennathur, A., \& Kansal, A. (1999). Nonfatal occupational injuries in the United States Part III-injuries to the upper extremities. International Journal of Industrial Ergonomics, 25, 151-169. http://dx.doi.org/10.1016/S0169-8141(98)00104-8

Naylor, Y. K., \& Amazeen, E. L. (2004). The size-weight illusion in team lifting. Human Factors, 46(2), 349-356. http://dx.doi.org/10.1518/hfes.46.2.349.37336

Okunribido, O. O., \& Haslegrave, C. M. (1999). Effect of handle design for cylinder trolleys. Applied Ergonomics, 30, 407-419. http://dx.doi.org/10.1016/S0003-6870(98)00053-2

Putz Anderson, V. (1988). Cumulative trauma disorders: manual for musculoskeletal diseases of the upper limbs. Taylor \& Francis, Bristol, PA.

Roquelaure, Y., D’Espagnac, F., Delamarre, Y., \& Fontbonne, D. P. (2004). Biomechanical assessment of new $\begin{array}{lllll}\text { hand-powered pruning } & \text { shears. }\end{array}$ http://dx.doi.org/10.1016/j.apergo.2003.11.006

Silverstein, B. A., Fine, L. J., \& Armstrong, T. J. (1986). Hand wrist cumulative trauma disorders in industry. British Journal of Industrial Medicine, 43, 779-784. http://dx.doi.org/10.1136/oem.43.11.779

Silverstein, B. A., Fine, L. J., \& Armstrong, T. J. (1987). Occupational factors and carpal tunnel syndrome. American Journal of Industrial Medicine, 11, 343-358. http://dx.doi.org/10.1002/ajim.4700110310

Tichauer, E. R., \& Gage, H. (1977). Ergonomics principles basis to hand tool design. American Industrial Hygiene Association Journal, 38, 103-116. http://dx.doi.org/10.1080/00028897708984406

Tichauer, E. R. (1978). The Biomechanical Basis of Ergonomics: Anatomy Applied to the Design of Work Station. Wiley, New York, USA.

Waters, T. R. (2004). National efforts to identify research issues related to prevention of work-related musculoskeletal disorders. International Journal of Industrial Ergonomics, 14, 7-12. http://dx.doi.org/10.1016/j.jelekin.2003.09.004

Wu, S. P., \& Hsieh, C. S. (2002). Ergonomics study on the handle length and lift angle for the culinary spatula. Applied Ergonomics, 33, 493-501. http://dx.doi.org/10.1016/S0003-6870(02)00024-8

Wu, S. P., Ho, C. P., \& Yen, C. L. (2011). The effect of wok size and handle angle on the maximum acceptable weights of wok flipping by male cook. Industrial Health, 49, 755-764. http://dx.doi.org/10.2486/indhealth.MS1178

Wu, S. P., Yang, C. H., Lin, C. H., \& Pai, P. K. (2015). Ergonomic Design og Bent-Handled Culinary Spatula for Female Cook's Stir-Frying Task. J Food Process Technol, 6, 476.

You, D., Smith, A. H., \& Rempel, D. (2014). Meta-analysis: association between wrist posture and carpal tunnel syndrome among workers. Safety and Health at Work, 5(1), 27-31. http://dx.doi.org/10.1016/j.shaw.2014.01.003 


\section{Copyrights}

Copyright for this article is retained by the author(s), with first publication rights granted to the journal.

This is an open-access article distributed under the terms and conditions of the Creative Commons Attribution license (http://creativecommons.org/licenses/by/3.0/). 